\title{
Investigation of the force effect of the vibrating working body of the slitter on the soil
}

\author{
Mikhail Konstantinov ${ }^{1, *}$, Sergey Drozdov ${ }^{1}$, Vitaly Mukhamedov ${ }^{1}$, Beket Nuralin², and \\ Manarbek Galiev² \\ ${ }^{1}$ Federal state budgetary educational institution of higher education «Orenburg state agrarian \\ University», Orenburg, Russia \\ ${ }^{2}$ West Kazakhstan agrarian and technological University, Republic of Kazakhstan
}

\begin{abstract}
The theory of the force action of the working body of the slitter on the ground is considered. It is proposed to divide this force into four components: the force of cutting the material, the force of overcoming the friction forces acting on the ground, the force of cracking the material and the force of resistance of the ground environment. Theoretical dependences for determining the components of the tool's traction resistance when using vibration are proposed. As a result of theoretical and experimental studies, it was found that due to the vibration effect of the working body of the slot rod, the traction resistance is reduced by $13.8 \%$. The decrease is due to changes in the physical and mechanical properties of the soil under the influence of directional vibrations.
\end{abstract}

\section{Intduction}

Since the invention of the plow, the problem of determining the force required for its traction has arisen. Based on large experimental data, V. P. Goryachkin derived a rational formula for soil treatment with a reservoir turnover [1]

$$
R=f \cdot G+k \cdot a \cdot b+\xi \cdot a \cdot b \cdot V^{2},
$$

where $\mathrm{R}$ is the traction resistance of the plough, $\mathrm{N}$;

$\mathrm{f}$ - coefficient of resistance to movement of the plow;

$\mathrm{G}$ - the weight of the plow, $\mathrm{H}$;

$\mathrm{K}$ - coefficient of soil resistivity, $\mathrm{N} / \mathrm{m}^{2}$;

a - depth of ploughing, $\mathrm{m}$;

$\mathrm{b}$ - width of the plough, $\mathrm{m}$;

$\varepsilon$-coefficient depending on the properties of the soil and the size of the soil layer, $\mathrm{H} \cdot \mathrm{c}^{2} / \mathrm{M}^{4}$

$\mathrm{V}$ - operating speed of the unit, $\mathrm{m} / \mathrm{s}$.

Tillage machines were improved, new technologies and methods were offered, and the range of working bodies for basic tillage was expanded. Therefore, formula (1) can not

\footnotetext{
* Corresponding author: miconsta@yandex.ru
} 
always be used. In addition, the coefficients in a rational formula can only be determined experimentally.

Many scientists for each method of basic soil cultivation offer their own theories, hypotheses and calculation methods for determining the traction resistance of the tool. But the end result should be the convergence of theoretical results with practical values, which is not always the case. The reason for this is a lot of assumptions, incorrect accounting of the physical and mechanical properties of the soil, and other factors that affect the traction resistance.

In his theory of force action of the working body in the form of delegates on the ground, we propose a force be divided into four stages: stress in shear of the material, the force to overcome the frictional forces working on the ground, the force on the destruction of the material, the resistance force of the soil environment.

\section{Methodology}

The processed soil material can be represented as a cut-out element in the form of a parallelepiped (Fig. $1 \mathrm{a}$, b). Then the selected element will be deformed, for which we can apply the generalized Hooke's law [2]. Let's select any geometric XYZ axes.

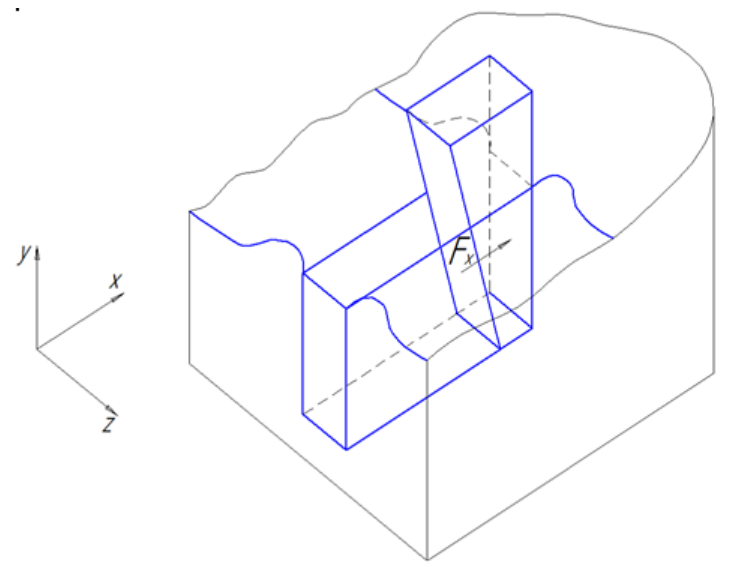

a)

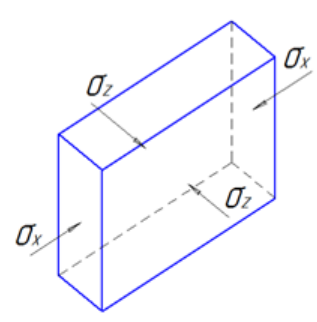

b)

Fig. 1. Diagram of the impact of the working body on the soil: a) the force acting on the soil layer from the working body, b) stresses arising in the cut soil element

$$
\left\{\begin{array}{l}
\varepsilon_{x}=\frac{\sigma_{x}}{E}-\frac{\mu}{E} \cdot\left(\sigma_{y}+\sigma_{z}\right) \\
\varepsilon_{y}=\frac{\sigma_{y}}{E}-\frac{\mu}{E} \cdot\left(\sigma_{x}+\sigma_{z}\right), \\
\varepsilon_{z}=\frac{\sigma_{z}}{E}-\frac{\mu}{E} \cdot\left(\sigma_{x}+\sigma_{y}\right)
\end{array}\right.
$$

where $\varepsilon_{\mathrm{x}}, \varepsilon_{\mathrm{y}}, \varepsilon_{\mathrm{z}}-$ is the total relative deformation in the direction of the $\mathrm{x}, \mathrm{y}$, and $\mathrm{z}$ axes, respectively;

$\sigma_{\mathrm{x}}, \sigma_{\mathrm{y}}, \sigma_{\mathrm{z}}-$ normal stresses acting in the direction of the axes XYZ, respectively, $\mathrm{Pa}$;

$\mu$-Poisson's ratio;

E-modulus of longitudinal elasticity, Pa. 
Due to the action of the force $F_{X}$ in its direction, a voltage $\sigma_{x}$ occurs. The appearance of lateral stress $\sigma \mathrm{z}$ is explained by the fact that under the action of stress $\sigma \mathrm{x}$, perpendicular to the pressure pad, the material of the cut element tends to spread out to the sides. Respectively $\sigma_{\mathrm{x}}=-\sigma_{\mathrm{x}}, \sigma_{\mathrm{y}}=0, \sigma_{\mathrm{z}}=-\sigma_{\mathrm{z}}$. Then

$$
\left\{\begin{array}{l}
\varepsilon_{x}=-\frac{\sigma_{x}}{E}+\frac{\mu \cdot \sigma_{z}}{E} \\
\varepsilon_{y}=\frac{\mu \cdot \sigma_{x}}{E}+\frac{\mu \cdot \sigma_{z}}{E} \\
\varepsilon_{z}=-\frac{\sigma_{z}}{E}+\frac{\mu \cdot \sigma_{x}}{E}
\end{array}\right.
$$

We Express the normal stresses $\sigma_{\mathrm{x}}$ and $\sigma_{\mathrm{z}}$ in terms of dynamic stresses [2]. The strength condition will look like this

$$
\sigma_{\partial u н}=k_{\partial u н} \cdot \sigma_{c m} \leq \sigma_{b}
$$

where $\sigma_{\text {din }}$-dynamic stresses, $\mathrm{Pa}$;

$\mathrm{k}_{\mathrm{din}}$ - dynamic coefficient of;

$\sigma_{\text {st }}$ - stresses that occur in the material under static loading, Pa;

$\sigma_{\text {al }}$ - allowable stress to soil compression, Pa.

When a sudden load is applied, the dynamic stresses are twice as large as the static load action, i.e. $\mathrm{k}_{\mathrm{din}}=2$ [2]. Accordingly, given the direction of stress action in the cut element, we can present equation (4) in this form

$$
\sigma_{x}=\sigma_{z}=\frac{\sigma_{b}}{k_{\partial u н}}
$$

Having solved each equation of the system (3), we determine the relative deformation of the cut element in the direction of the XYZ axes.

However, in sections within the body close to the surface where the forces are applied, the stresses are distributed over it not according to the Saint-Venant principle (evenly), but in the form of a parabola. And in the middle of the section, they are equal to twice the value. The stress equalization along the entire cross section will occur at a distance from the body surface equal to the cross-section width [3].

Thus, the stresses that occur in the cut element of the soil can be represented as

$$
\begin{gathered}
\sigma_{x}=\frac{2 F_{x}}{A_{x}}, \\
\sigma_{z}=\frac{2 F_{z}}{A_{z}},
\end{gathered}
$$

where $F_{x}$ is the force acting on the soil element from the working body in the direction of its movement, $\mathrm{N}$; $\mathrm{N}$;

$\mathrm{F}_{\mathrm{z}^{-}}$force acting in the transverse direction from the soil mass on the selected element,

$\mathrm{A}_{\mathrm{x}}$ - the cross-sectional area of the front part of the cut element, $\mathrm{m}^{2}$;

$\mathrm{A}_{\mathrm{Z}}$ - the cross-sectional area of the side of the cut element, $\mathrm{m}^{2}$. 
The effort spent on the destruction of soil material in the form of a cut element is determined using the first and third equations of the system (3), taking into account the dependencies (6) and (7)

$$
\left\{\begin{array}{l}
\varepsilon_{x}=-\frac{2 F_{x}}{A_{x} \cdot E}-\frac{\mu}{E} \cdot\left(\sigma_{y}-\sigma_{z}\right) \\
\varepsilon_{z}=-\frac{2 F_{z}}{A_{z} \cdot E}-\frac{\mu}{E} \cdot\left(-\sigma_{x}+\sigma_{y}\right)
\end{array}\right.
$$

We Express the forces Fx and Fz from the equation of the system (8)

$$
\left\{\begin{array}{l}
F_{x}=-\frac{A_{x}}{2} \cdot\left(\mu \cdot \sigma_{z}-E \cdot \varepsilon_{x}\right) \\
F_{z}=-\frac{A_{z}}{2} \cdot\left(\mu \cdot \sigma_{x}-E \cdot \varepsilon_{z}\right)
\end{array},\right.
$$

When moving the soil along the working body relative to each other, a friction force will occur (Fig. 2).

The friction force of the soil on the front of the working body is determined by the formula

$$
F_{m p 1}=f_{c} \cdot F_{x}
$$

where $f_{c}$ is the coefficient of friction of the soil on steel.

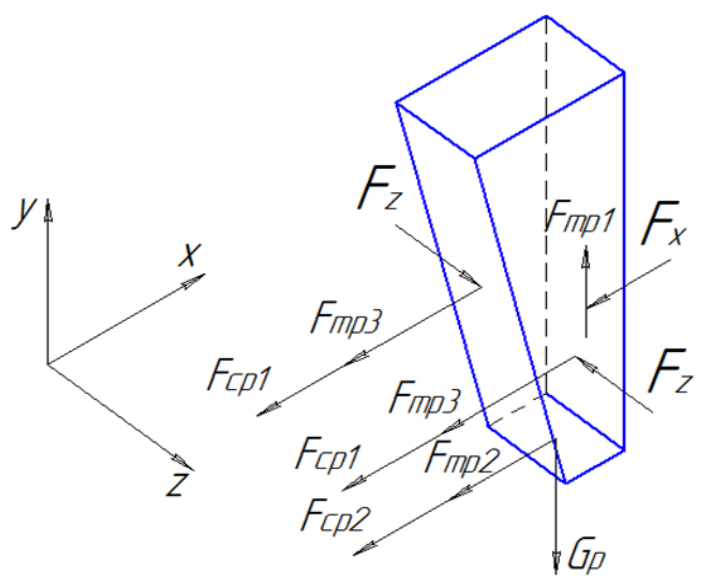

Fig. 2. Diagram of the power effect of soil on the working body.

The friction force of the working body on the bottom of the resulting gap is found

$$
F_{m p 2}=f_{c} \cdot G_{p}
$$

where $\mathrm{G}_{\mathrm{P}}$ is the weight acting on the working body, $\mathrm{N}$.

The friction force of the soil against the side wall of the working body due to the effect of "jamming" from the force Fz can be determined by the formula

$$
F_{m p 3}=n_{c m} \cdot f_{c} \cdot F_{z},
$$


where $\mathrm{n}_{\mathrm{ST}}$ is the number of sides affected by the force Fz.

The force resistance of the movement of the working body of the slitter in the medium is determined by

$$
F_{C . C}=k_{c} \cdot A_{n} \cdot \frac{\rho \cdot V_{A}^{2}}{2},
$$

where $k_{c}$ is the coefficient of resistance, depends on the shape of the working body;

$\mathrm{A}_{\Pi}$ - the area of the projection of the working body in the plane of its movement in the soil, $\mathrm{m}^{2}$;

$\rho$ is the soil density, $\mathrm{kg} / \mathrm{m}^{3}$;

$V_{A}^{2}$ - the speed of movement of the working body, $\mathrm{m} / \mathrm{s}$.

In addition, the soil element must be broken up before it is separated from the General array . In this case, efforts should also be taken into account

cross-section of the working body of the soil (Fig. 2) [2].

$$
F_{c p 1}=n_{c p} \cdot A_{1} \cdot\left[\tau_{c p}\right]
$$

where $\mathrm{n}_{\mathrm{cp}}$ is the number of slice surfaces;

$\mathrm{F}_{\mathrm{cp} 1}$ - the force of cutting the soil by the sides of the working body, $\mathrm{N}$;

$\mathrm{A}_{1-}$ the cut-off area, $\mathrm{m}^{2}$;

$\left[\tau_{\mathrm{cp}}\right]$ - permissible tangent stresses on the cut, $\mathrm{Pa}$.

$$
F_{c p 2}=A_{2} \cdot\left[\tau_{c p}\right]
$$

where $\mathrm{F}_{\mathrm{cp} 2}$-the force of the soil cutting by the working body along the bottom of the gap, $\mathrm{N}$;

\section{Results and discussion}

Finally we can get the equation of the traction resistance of the working body of the slotted tool

$$
R=F_{x}+F_{m p 1}+F_{m p 2}+F_{m p 3}+F_{c p 1}+F_{c p 2}+F_{c . c},
$$

The results of theoretical calculations of the traction resistance of the working body of the slitter are shown on the graph (Fig. 3).

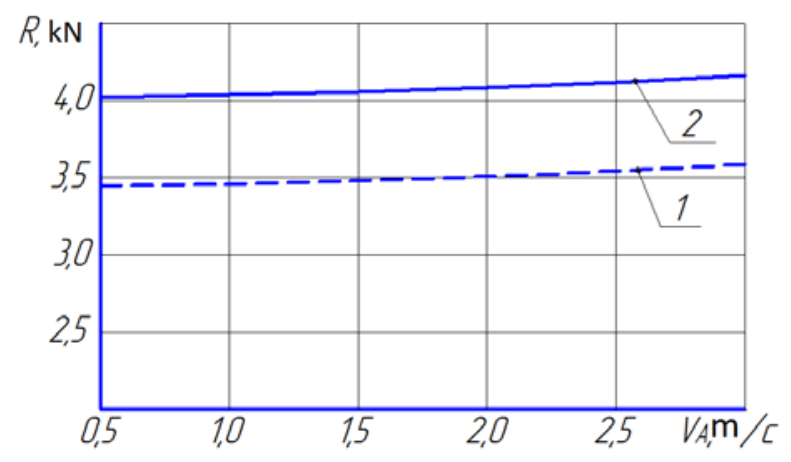

Fig. 3. Dependence of the traction resistance of the working body from the speed of its movement: 1-active working body; 2-passive working body 


\section{Conclusions}

The results of theoretical and experimental studies show that due to the vibration effect of the working body of the slitter, the traction resistance is reduced by $13.8 \%$. The decrease is due to changes in the physical and mechanical properties of the soil during the influence of directional vibrations.

\section{References}

1. Goryachkin, V. P. Collected works. In 3 vols. / edited by N. D. Luchinsky / V. P. Goryachkin. Moscow: Kolos, 1965. - Vol. 2. - P. 459.

2. Kochetov, V. T. Resistance of materials. Rostov-on-don: Rostov University Press. 1987. - Pp. 79-86.

3. Konstantinov M. M. Vibrational interaction of the working organ with the soil [Text] / M. M. Konstantinov, S. N. Drozdov, I. V. Trofimov // Scientific review. - 2017. - № 20. - Pp. 58-64. 